\title{
Evaluation of endotracheal-suctioning practices of critical-care nurses - An observational correlation study
}

\author{
Miia J ansson¹, Tero Ala-Kokko², Pekka Ylipalosaari ${ }^{3}$, Helvi Kyngäs ${ }^{1}$ \\ 1. Institute of Health Sciences, University of Oulu, Finland, Finland. 2. Division of Intensive Care, Department of \\ Anesthesiology, Oulu University Hospital, Oulu, Finland. 3. Division of Intensive Care and Infection Control, Oulu \\ University Hospital, Oulu, Finland.
}

Correspondence: Miia Jansson. Address: University of Oulu, Institute of Health Sciences, BOX 5000, 90014 University of Oulu, Finland. Email: miiajans@mail.student.oulu.fi.

Received: August 14, 2012

Accepted: September 26, 2012

Online Published: January 15, 2013

DOI : $10.5430 /$ jnep.v3n7p99

URL: http://dx.doi.org/10.5430/jnep.v3n7p99

\section{Abstract}

Background: Endotracheal-suctioning (ETS) is a procedure that may constitute a risk factor for ventilator-associated pneumonia (VAP) by increasing microbial colonization of the lower airway. Unsafe ETS practices have been observed worldwide during recent years. Because of adverse reactions, practioners need to take all necessary precautions to ensure patient safety and a high quality of nursing care. The aim of the present study was to evaluate critical-care nurses' performance in relation to current recommendations in their daily practice prior to, during and post ETS events.

Methods: A structured, non-participatory, observational study $(\mathrm{n}=40)$ was conducted using a 25 -item best-practice information sheet to assess critical-care nurses' ETS practices in a mixed medical-surgical intensive-care unit. Onesample- and independent-samples $t$-tests were used to compare critical-care nurses' ETS performance against current recommendations within different ICU experience groups.

Results: The quality of observed ETS practices was significantly lower than the required quality of care $(p<0.001)$. The most significant discrepancies were observed in ETS practices related to infection-control practices.

Conclusion: Critical-care nurses are currently not following current ETS recommendations. Significant discrepancies, which may constitute a risk factor for VAP by increasing microbial colonization of the lower airway, were identified. Unsafe ETS practices may jeopardize patient safety, and thus the quality of nursing care. Educational interventions, clinical guidelines and adequate support need to be provided to critical-care nurses to assess and improve their professional capabilities and current practice. Regular auditing and prompt feedback would be beneficial.

\section{Key words}

Ventilator-associated pneumonia, Endotracheal-suctioning, Nursing, Patient safety, Quality of nursing care

\section{I ntroduction}

Endotracheal-suctioning (ETS) is probably one of the most common invasive procedures performed in patients with an artificial airway ${ }^{[1]}$. ETS is used to enhance clearance of respiratory-tract secretions, improve oxygenation and prevent 
atelectasis ${ }^{[2]}$. Infected biofilm in the endotracheal tube and unsafe ETS practices (e.g., inadequate infection-control practices and the prevention of potential aspiration of colonized oropharyngeal secretions) have been suggested to be the main treatment-related risk factors in the pathogenesis of ventilator-associated pneumonia (VAP) by increasing microbial colonization of the lower airway ${ }^{[1,3]}$.

Previous prevalence and prospective cohort studies ${ }^{[4-6]}$ have shown that VAP is associated with a two-fold mortality ${ }^{[4]}$ and morbidity rates, excessive length of intensive care unit (ICU) and hospital stays, and high hospital costs ${ }^{[7]}$. In previous descriptive, observational, before-after ${ }^{[8,9]}$ and correlational studies, ETS practices have been evaluated in relation to current recommendations ${ }^{[8-11]}$. Despite a lack of robust evidence, unsafe practices have been observed worldwide over the past few years. Significant discrepancies have been observed in practices prior to (e.g., ETS-assessment techniques, hyper oxygenation), during (e.g., infection-control practices, the level of negative pressure used to clear secretions) and post endotracheal suctioning (e.g., patients' reassurance) ${ }^{[10,11]}$. Because of the risk of adverse reactions, such as hypoxemia and hemodynamic alternations, infections, barotraumas, bronchospasms and atelectasis, practioners need to take all necessary precautions to ensure patient safety and the quality of nursing care ${ }^{[1]}$.

The aim of this study was to evaluate critical-care nurses' performance in relation to current recommendations in their daily practice prior to, during and post ETS events. The main questions addressed were as follows: What are critical-care nurses' practices prior to, during and post ETS events, and how do practices differ from current recommendations?

\section{Methods}

\subsection{Design}

A cross-sectional quantitative correlation study.

\subsection{Setting}

The study was carried out in a single academic center in a 22-bed adult, mixed medical-surgical ICU in Finland in autumn 2010. The population of interest were critical-care nurses $(n=40)$. The inclusion criteria were all nursing staff, working part- or full-time, including registered and practical nurses, who provided care for mechanically-ventilated, adult patients with an artificial airway. Participants were selected for the study using a non-probability method of sampling.

\subsection{Data collection}

Observation was conducted in the participants' natural environments. ETS practices were observed during morning (07:00-15:00) and evening (14:30-21:30) shifts in nursing-care and extubation contexts. Oral informed content was obtained for each participant after being briefed about the study's aim and procedure. It was explained to participants that observations would be made to explore nursing-care practices related to VAP prevention.

Observation data were collected using a 25-item structured best-practice information sheet related to tracheal suctioning of adults with an artificial airway (see Table 2). The best-practice information sheet was adapted, translated and evaluated by two critical-care experts - one physician and one registered nurse - from McKillop's and Kelleher and Andrews's previously validated and pre-tested tools ${ }^{[8,10]}$. The best-practice information sheet was divided into four sections: practices prior to ETS event, infection-control practices, practices during and post ETS event. The maximum score was 25 points and the minimum score was zero points. If participants adhered to an item in the recommended procedure, they were assigned one point. 


\subsection{Data analysis}

SPSS 18.0 for Windows was used for statistical analysis (SPSS Inc., Chicago, Illinois, USA). Descriptive statistics were used to evaluate demographics and practices prior to ETS event, infection-control practices, practices during and post ETS event.

The one-sample t-test was used to compare critical-care nurses' ETS performance against current recommendations. Moreover, the independent-samples t-test was used to compare critical-care nurses' ETS performance against current recommendations within different ICU experience groups (i.e., $\leq 5 \mathrm{yrs}$ vs. $>5 \mathrm{yrs}$ and $\leq 10 \mathrm{yrs}$ vs. $>10 \mathrm{yrs}$ ). A $p$-value less than 0.05 were considered statistically significant.

\subsection{Ethical considerations}

In Finland, according to the Medical Research Act (488/1999 and amendments 295/2004), the approval of the local ethics committee is not required for studies focusing on staff members. Oral informed content was obtained for each participant after being briefed about the study. In addition, the participants were informed that participation in the study was voluntary. Confidentiality and anonymity were assured by coding the data. The data were stored and protected on password-protected computer. Only the corresponding author (M.J.) had access to the data. Each participant was observed on a single occasion ${ }^{[12]}$.

\section{Results}

\subsection{Critical-care nurses' demographics}

Forty critical-care nurses participated in the study. Demographic information for the study participants is shown in Table 1. The majority of participants were registered nurses (98\%) with > 10 years ICU experience $(42.5 \%)$.

Table 1. Participants' (critical-care nurses) demographics

\begin{tabular}{ll}
\hline Nurse variables $(\mathbf{n}=\mathbf{4 0})$ & $\mathbf{n}(\%)$ \\
\hline ICU experience & \\
$<1$ years & $5(12.5)$ \\
$1-5$ years & $12(30.0)$ \\
$6-10$ years & $6(15.0)$ \\
$>10$ years & $17(42.5)$ \\
Education & \\
Registered nurse & $39(97.5)$ \\
Practical nurse & $1(2.5)$ \\
\hline
\end{tabular}

\subsection{Quality of treatment}

Compared to the best-practice information sheet, the average scale score was 13.73 out of 25 points (8-19; SD 2.66). The one-sample $t$-test identified significant differences $(p<0.001)$ between the quality of treatment provided and that required. There were no significant differences in average scale scores within different ICU experience groups.

\subsection{Critical-care nurses' ETS practices prior to, during and post ETS events}

Significant treatment-related discrepancies were observed in infection-control practices related to prevention of crossinfections and the potential risk of aspiration of colonized oropharyngeal secretions prior to and post ETS events (see 
Table 2). Technical discrepancies were observed in practices prior to (e.g., ETS-assessment techniques, hyper oxygenation) and during (e.g., the level of negative pressure used to clear secretions) ETS events (see Table 2).

Table 2. Critical-care nurses' performance in relation to current recommendations in their daily practice prior to, during and post endotracheal-suctioning events

\begin{tabular}{|c|c|}
\hline Practices prior to, during and post ETS event $(n=40)$ & $n(\%)$ of participants observed \\
\hline \multicolumn{2}{|l|}{ Practices prior to ETS event } \\
\hline 1. Patient assessment: Patient' chest auscultation before ETS? & $2(5.3)$ \\
\hline 2. Patient preparation: Explaining to patient about the procedure & $24(61.5)$ \\
\hline 3. Pre suctioning hyperoxygenation & $23(57.5)$ \\
\hline 4. Cuff pressure checked* & $21(56.8)$ \\
\hline 5. Protection of eyes from secretions* & $10(25.0)$ \\
\hline 6. Protection of central venous catheter from secretions* & $26(65.0)$ \\
\hline 7. Analgesic administered* & $8(21.1)$ \\
\hline \multicolumn{2}{|l|}{ Infection-control practices } \\
\hline 8. Hand disinfection prior to suctioning & $26(72.2)$ \\
\hline 9. Gloves worn & $40(100.0)$ \\
\hline 10. Apron worn & $13(32.5)$ \\
\hline 11. Face mask worn & $39(97.5)$ \\
\hline 12. Sterility of suction catheter maintained until inserted into airway & $25(67.6)$ \\
\hline \multicolumn{2}{|l|}{ The ETS event } \\
\hline 13. Sodium chloride instillation & $10(25.0)$ \\
\hline 14. Size of suction catheter ( $\leq$ Half of internal diameter of ETT) & $38(100.0)$ \\
\hline 15. Number of suction passes $\leq 2$ & $30(75.0)$ \\
\hline 16. Duration of suction applied to airway ( $<15$ seconds) & $29(72.5)$ \\
\hline 17. Level of suction pressure $80-150 \mathrm{mmHg}$ & $6(15.0)$ \\
\hline 18. Two nurses working as team to create suction* & $34(85.0)$ \\
\hline \multicolumn{2}{|l|}{ Post ETS practices } \\
\hline 19. Patient reconnected to oxygen within 10 seconds post suctioning & $33(89.2)$ \\
\hline 20. Post-suctioning hyper oxygenation & $25(62.5)$ \\
\hline 21. Post-ETS assessments: Patients' chest auscultation after suctioning & $0(0.0)$ \\
\hline 22. Patient reassured & $21(55.3)$ \\
\hline 23. Hand disinfection post suctioning & $21(52.5)$ \\
\hline $\begin{array}{l}\text { 24. Used catheter and gloves disposed of in a manner that prevents contamination from } \\
\text { secretions }\end{array}$ & $24(61.5)$ \\
\hline 25. Cuff pressure checked* & $6(23.1)$ \\
\hline
\end{tabular}

Note. ETT=Endotracheal tube

* Supplemented in Kelleher and Andrews' (2008) original instrument

\section{Discussion and conclusion}

\subsection{Discussion}

Significant treatment-related discrepancies were observed in critical-care nurses' performance in relation to current recommendations in their daily practice prior to and during ETS events. The most significant discrepancies were observed in ETS practices related to infection-control practices. 
Infection-control practices (e.g., hand hygiene, protection of practioners and patients from secretions as well as adequate disposal of the used catheter and gloves, and maintenance of the sterility of the suction catheter) are crucial elements in the prevention of cross-infections and transmission of pathogens via hands or equipment ${ }^{[13]}$. Adequate hand hygiene has been associated with a significant reduction in $\operatorname{VAP}^{[14]}$. As found in previous studies ${ }^{[8-11]}$, the principal deficiency was in hand disinfection practices prior to and post ETS events. In addition to infection-control practices, significant treatment-related discrepancies were observed in maintaining an optimal cuff pressure prior to and post ETS events, which is essential for the prevention of micro-aspiration of colonized oropharyngeal secretions.

Technical discrepancies were observed in the ETS practices prior to (e.g., ETS-assessment techniques, hyper oxygenation) and during (e.g., the level of negative pressure used to clear secretions) ETS events, which are related to the potential risk of hypoxemia and hemodynamic alternations, infections, barotraumas, bronchospasms and atelectasis ${ }^{[1,2]}$. The primary goal for patients who have an artificial airway is to ensure airway patency and optimal oxygenation ${ }^{[2]}$. In agreement with the findings of Kelleher ${ }^{[10]}$ and Day ${ }^{[1]}$, the main deficiencies were related to hyper oxygenation prior to and post ETS practices as well as in maintaining an adequate suction pressure $(<80-150 \mathrm{mmHg})$. As found in previous studies ${ }^{[8-10]}$, the majority of suctions were carried out without clinical indicators (related to chest auscultation) being identified ${ }^{[1,15]}$. Previous studies have shown that the risk of overlooking residual secretions is decreased if assessment is performed using a stethoscope ${ }^{[16]}$.

The identified deficiencies may be due to a lack of knowledge ${ }^{[11]}$ and directions ${ }^{[10]}$, poor self-efficacy, time-related barriers ${ }^{[17]}$ and inadequate data collection in extubation situations. Our findings are in line with several previous studies ${ }^{[8-11]}$. In this, as in previous studies ${ }^{[10]}$, it was evident that ETS practices were largely based on routine rather than research or current recommendations. However, it should be borne in mind that the participants may have followed recommendations more closely than usual because they were conscious of being observed. If this is the case, the quality of ETS practices may be even worse than suggested by the results.

\subsection{Limitations}

The 25-item structured best-practice information sheet was not pilot-tested in the current context. However, two ICU experts were responsible for adaptation, translation and content evaluation of the original pre-validated instruments, which were based on the best-practice recommendations for ETS practices related to tracheal suctioning of adults with an artificial airway.

The study was conducted in a single university hospital and involved a nonprobability method of sampling, which may increase the risk of bias. In addition, the sample size was not assessed for statistical significance. However, the sample was of sufficient size to reveal differences between critical-care nurses' performance in relation to current recommendations. The findings are in line with previous, including some using other instruments. Furthermore, the study was not designed to identify correlations between ETS practices and the incidence of VAP.

\subsection{Conclusions}

Critical-care nurses are currently not following current recommendations. The most significant discrepancies were observed on infection-control practices, which may constitute important risk factors for VAP by increasing microbial colonization of the lower airway. The observed deficiencies may jeopardize patient safety and, thus the quality of nursing care.

The knowledge acquired can be used to develop clinical practice. There is a current need for studies that evaluate whether ETS guidelines prevent VAP. New, innovative educational interventions, clinical guidelines and adequate support need to be provided to nurses to assess and enhance their professional capabilities and current practices. Education should focus on the basic principles and practices for preventing transmission of infectious agents ${ }^{[18]}$, including information about local epidemiology, patient- and treatment-related risk factors as well as clinical outcomes ${ }^{[19]}$. In addition, education should 
include information about patient-safety standards, together with risk and safety measures in place to reduce or prevent errors or harm ${ }^{[20]}$, including current ETS recommendations. Regular auditing and prompt feedback would be beneficial.

According to current recommendations, sterile technique is also encouraged during the open-suctioning procedure ${ }^{[1]}$. The latter recommendation is probably justified based on the observed poor compliance of health-care practioners to appropriate hand hygiene. Further research is needed to explore health-care providers hand hygiene compliance, with a focus on hand-disinfection technique and duration, in invasive, high-risk situations such as ETS.

\section{Contributions}

MJ, TAK and HK contributed to study design. MJ contributed to data collection and analysis. MJ, TAK, PY and HK contributed to manuscript preparation.

\section{Acknowledgements}

This study was financed by Oulu University Hospital. The authors wish to thank all the critical-care nurses who participated in this study. Also, the help of Mrs. H. Laukkala with statistical analysis is highly appreciated.

\section{References}

[1] American Association for Respiratory Care (AARC). Clinical Practice Guidelines. Endotracheal suctioning of mechanically ventilated patients with artificial airways. Respiratory Care. 2010; 55: 758-64. PMid:20507660

[2] Subirana M, Sola' I, Benito S. Closed tracheal suction systems versus open tracheal suction system for mechanically ventilated adult patients (Review). The Cochrane Database of Systematic Reviews. 2010; 7: 1-50.

[3] American Thoracic Society Documents (ATS). Guidelines for the Management of Adults with Hospital-acquired, Ventilator-associated, and Healthcare-associated Pneumonia. American Journal of Respiratory and Critical Care Medicine. 2005; 171: 388-416. PMid:15699079 http://dx.doi.org/10.1164/rccm.200405-644ST

[4] Safdar N, Dezfulian C, Collard HR. Clinical and economic consequences of ventilator-associated pneumonia: A systematic review. Critical Care Medicine. 2005; 33: 2184-2193. PMid:16215368 http://dx.doi.org/10.1097/01.CCM.0000181731.53912.D9

[5] Ylipalosaari P, Ala-Kokko T, Laurila J, Ohtonen P, Syrjälä H. Intensive care acquired infection is an independent risk factor for hospital mortality: a prospective cohort study. Critical Care. 2006; 10: R66. PMid:16626503 http://dx.doi.org/10.1186/cc4902

[6] Lyytikäinen O, Kanerva M, Aghte N, Möttönen T, Ruutu P. Healthcare-associated infections in Finnish acute care hospitals: a national prevalence survey, 2005. Journal of Hospital Infection. 2008; 69: 288-294. PMid:18439716 http://dx.doi.org/10.1016/j.jhin.2008.03.005

[7] Chen Y-Y, Wang F-D, Chou P. Incidence rate and variable cost of nosocomial infections in different types of intensive care units. Infection Control and Hospital Epidemiology. 2009; 30: 39-46. PMid:19046058 http://dx.doi.org/10.1086/592984

[8] McKillop A. Evaluation of the implementation of a best practice information sheet: tracheal suctioning of adults with an artificial airway. Joanna Briggs Institute Reports. 2004; 2: 293-308.

[9] Özden D, Görgülü RS. Development of standard practice guidelines for open and closed system suctioning. Journal of Clinical Nursing. 2012; 21: 1327-1338. PMid:22390197 http://dx.doi.org/10.1111/j.1365-2702.2011.03997.x

[10] Kelleher S, Andrews T. An observational study on the open-system endotracheal suctioning practices of critical care nurses. Journal of Clinical Nursing. 2008; 17: 360-369. PMid:18205692 http://dx.doi.org/10.1111/j.1365-2702.2007.01990.x

[11] Day T, Farnell S, Haynes S, Wainwright S, Wilson-Barnett J. Tracheal suctioning: an exploration of nurse's knowledge and competence in acute and high dependency ward areas. Journal of Advanced Nursing. 2002; 39: 35-45. PMid:12074750 http://dx.doi.org/10.1046/j.1365-2648.2002.02240.x

[12] Polit D, Beck C. Nursing Research. Generating and Assessing Evidence for Nursing Practice. Eight Editions. Lippincott Williams \& Wilkins, Philadelphia, 2008.

[13] World Health Organization (WHO). WHO Guidelines on Hand Hygiene in Health Care. First Global Patient Safety Challenge Clean Care is Safer Care. WHO, 2009.

[14] Koff MD, Corwin HL, Beach ML, Surgenor SD, Loftus RW. Reduction in ventilator associated pneumonia in a mixed intensive care unit after initiation of a novel hand hygiene program. Journal of Critical Care. 2011; 26: 489-495. PMid:21439767 http://dx.doi.org/10.1016/j.jcrc.2010.12.013 
[15] Pedersen CM, Rosendahl-Nielsen M, Hjermind J, Egerod I. Endotracheal suctioning of adult intubated patient - What is the evidence? Intensive and Critical Care Nursing. 2009; 25: 2 -30. PMid:18632271 http://dx.doi.org/10.1016/j.iccn.2008.05.004

[16] Sole ML, Byers JF, Ludy JE, Zhang Y, Banta CM, Brummel K. A Multisite Survey of Suctioning Techniques and Airway Management Practices. American Journal of Critical Care. 2003; 12: 220-230. PMid:12751396

[17] De Wandel D, Maes L, Labeau S, Vereecken C, Blot S. Behavioral Determinants of Hand Hygiene Compliance in Intensive Care units. American Journal of Critical Care. 2010; 19: 230-239. PMid:20436062 http://dx.doi.org/10.4037/ajcc2010892

[18] Centers for Disease Control and Prevention (CDC). Guidelines for Isolation Precautions: Preventing Transmission of Infectious Agents 2007 Guideline for Isolation Precautions: Preventing Transmission of Infectious Agents in Healthcare Settings. Centers for Disease Control and Prevention (CDC). Siegel, J., Rhinehart, E., Jackson, M., Chiarello, L. The Healthcare Infection Control Practices Advisory Committee. 2007.

[19] Coffin SE, Klompas M, Classen D, Arias KA, Podgorny K, Anderson DJ, Burstin H, Calfee DP, Dubberke ER, Fraser V, Gerding DN, Griffin FA, Gross P, Kaye KS, Lo K, Marschall K, Mermel LA. Strategies to Prevent Ventilator-Associated Pneumonia in Acute Care Hospitals. Infection Control and Hospital Epidemiology S1, S31-S40.

[20] European Union (EU). Council Recommendation of 9 June 2009 on patient safety, including the prevention and control of healthcare associated infections. Official Journal of the European Union. 2009/C, 151/1-6. Available from:

http://ec.europa.eu/health/patient_safety/docs/council_2009_en.pdf 